\title{
Increased leukotriene B4 plasma concentration in type 2 diabetes individuals with cardiovascular autonomic neuropathy
}

\author{
Jose Antonio Januario Neves ${ }^{1}$, Mozânia Reis De Matos ${ }^{1,2}$, Theresa Ramalho ${ }^{3}$, Daniele Pereira Santos-Bezerra ${ }^{4}$, \\ Cristiane Das Graças Dias Cavalcante², Renata D’ Alpino Peixoto ${ }^{1}$, Márcia Silva Queiroz ${ }^{1}$, Sonia Jancar ${ }^{3}$ \\ and Maria Lucia Correa-Giannella $a^{1,4^{*}}$ (1)
}

\begin{abstract}
Background and aim: A low-grade inflammation is associated with cardiac autonomic neuropathy (CAN) and increased concentration of leukotriene B4 (LTB4) was found in individuals with type 1 diabetes and definitive CAN. This cross-sectional study evaluated plasma concentration of LTB4 and of other inflammatory mediators, namely, tumor necrosis factor (TNF), interleukin (IL)1B, and IL10 in individuals with type 2 diabetes (T2D) and different degrees of CAN, and correlated these inflammatory mediators with the degree of glycemic control and with a surrogate marker of insulin resistance.

Methods: TNF, IL1B, IL10 and LTB4 plasma concentrations were measured in 129T2D subjects (62\% women with [median] age of 63 years, disease duration of 8 years and $\mathrm{HbA1c}$ of 7.3\%) with or without CAN. The Lipid accumulation product index was used as a surrogate marker of insulin resistance.

Results: LTB4 concentration was significantly higher in those presenting incipient CAN $\left(69.7 \pm 16.6 \mathrm{pg} \mathrm{mL}^{-1}\right)$ and definitive CAN (71.5 $\left.\pm 15.7 \mathrm{pg} \mathrm{mL}^{-1}\right)$ versus those without CAN (57.0 $\left.\pm 13.9 \mathrm{pg} \mathrm{mL}^{-1}\right)$. The groups without CAN and with incipient CAN were pooled (group without definitive CAN) and compared to those with definitive CAN. LTB4 concentration was higher in the latter group, as well as TNF concentration, while IL10 concentration was lower in this group. After adjustment for confounding variables, only LTB4 concentration remained significantly different between the groups with and without definitive CAN. Plasma concentration of LTB4 did not correlate with the degree of glycemic control. After sorting the participants by sex, a borderline weak correlation was found between LTB4 and the Lipid accumulation product index in women.
\end{abstract}

Conclusion: In the T2D setting, circulating LTB4 concentration seems to be associated with cardiovascular dysautonomia.

Keywords: LTB4, Chronic diabetes complications, Inflammation, Insulin resistance

*Correspondence: m.giannella@uni9.pro.br

${ }^{1}$ Programa de Pos-Graduação Em Medicina, Universidade Nove de Julho (UNINOVE), Rua Vergueiro 235, $2^{\circ}$ subsolo, Pos-graduação, Sao Paulo CEP: 01504-001, Brazil

Full list of author information is available at the end of the article

\section{Background}

Chronic low-grade inflammation is present in obesity, being closely associated with the etiopathogenesis of insulin resistance and, consequently, with type 2 diabetes mellitus (T2D). Among the pro-inflammatory cytokines produced by the adipose tissue in visceral obesity are tumor necrosis factor (TNF), interleukin (IL) 1B and IL6.

(c) The Author(s) 2020. This article is licensed under a Creative Commons Attribution 4.0 International License, which permits use, sharing, adaptation, distribution and reproduction in any medium or format, as long as you give appropriate credit to the original author(s) and the source, provide a link to the Creative Commons licence, and indicate if changes were made. The images or other third party material in this article are included in the article's Creative Commons licence, unless indicated otherwise in a credit line to the material. If material is not included in the article's Creative Commons licence and your intended use is not permitted by statutory regulation or exceeds the permitted use, you will need to obtain permission directly from the copyright holder. To view a copy of this licence, visit http://creativeco mmons.org/licenses/by/4.0/. The Creative Commons Public Domain Dedication waiver (http://creativecommons.org/publicdomain/ zero/1.0/) applies to the data made available in this article, unless otherwise stated in a credit line to the data. 
On the other hand, in eutrophic individuals, the adipose tissue secretes anti-inflammatory cytokines, such as IL10 [1]. Studies in rodents have also implicated leukotriene B4 (LTB4) in the insulin resistance triggered by obesity [2].

Inflammation is also implicated in the etiopathogenesis of chronic complications of diabetes mellitus (DM). TNF and IL6 are produced by endothelial, mesangial and leukocyte cells, having already been associated with the development and progression of diabetic kidney disease and diabetic macroangiopathy [3].

Recently, we reported that in individuals with type 1 DM (T1D), those with worse glycemic control had higher plasma concentration of LTB4. Additionally, the analyses of this inflammatory marker according to the status of microvascular complications showed a higher plasma concentration of LTB4 in individuals with definitive cardiovascular autonomic neuropathy (CAN) as compared to individuals without this complication [4]. This finding possibly reflects a lower parasympathetic activity secondary to CAN, with impairment of the inflammatory reflex, a physiological mechanism by which the vagus nerve regulates the immune function and inhibits the excessive production of pro-inflammatory mediators [5].

In the present study, we aimed to evaluate the plasma concentrations of LTB4 and other inflammatory mediators, namely, TNF, IL1B and IL10 in individuals with T2D with and without CAN. In addition, we correlated the concentrations of these inflammatory mediators with the degree of glycemic control and with a surrogate marker of insulin resistance.

\section{Methods}

In this cross-sectional study, 129 individuals with T2D were selected from a cohort of 551 individuals recruited from a primary care unit in the city of São Paulo and evaluated for the CAN status between September 2018 and February 2019, as previously described. Briefly, a total of 583 out of the 1,853 T2D individuals followed in the unit agreed to participate; 32 individuals were not included because their capillary blood glucose was $>180 \mathrm{mg} / \mathrm{dL}^{-1}$ at the day of evaluation (hyperglycemia may interfere with the results of the autonomic tests) [6]. These 129 individuals were selected in order to form three groups matched for sex, age, DM duration and HbAlc: without CAN $(\mathrm{n}=44)$, with incipient CAN $(n=41)$ and with definitive CAN $(n=44)$. Thus, this study was performed in a convenience sample, since there was no sample size calculation. The groups without CAN and with incipient CAN were pooled (group without definitive CAN) and compared to those with definitive CAN. Participants were evaluated for demographic, clinical and biochemical characteristics, and for CAN status (by Ewing tests combined with spectral analysis of the heart rate [HR]). The diagnosis of incipient and definitive CAN was made, respectively, in presence of 2 and of $\geqslant 3$ abnormalities of HR variability and Ewing tests, as previously described [7]. The Lipid accumulation product (LAP) index was calculated as a surrogate marker of insulin resistance: (waist circumference [WC, in cm]-65) $\mathrm{x}$ triglycerides [TG, in $\mathrm{mmol} \mathrm{L}^{-1}$ ] in men and (WC-58) $x$ TG in women $[8,9]$. Plasma concentrations of TNF, IL1B, and IL10 were measured by BD Opt EIA ELISA Kit II (BD Biosciences, CA, USA) and LTB4 concentration was measured by the EIA kit (Cayman Chemical, MI, USA), according to the manufacturer's instructions. The statistical analyses were performed with JMP software version 8.0 (SAS Institute, Cary, NC, USA). The results are expressed as median \pm interquartile interval, except for the plasma concentrations of the inflammatory mediators, which are expressed as mean \pm standard deviation (SD). The differences between the groups with and without definitive CAN were assessed by Pearson's $\chi^{2}$ for the categorical variables and by Wilcoxon's test for the continuous variables. The Wilcoxon Kruskal-Wallis test followed by Dunn's post-test was employed to identify differences in the concentrations of the inflammatory mediators between the groups without CAN, with incipient and with definitive CAN. Logistic regression analyses with adjustment for confounding variables were employed to evaluate plasma concentrations of the inflammatory mediators between the groups with and without definitive CAN. Correlation analyses were performed by the Spearman's rank correlation coefficient. A $P$ value of $<0.05$ was considered statistically significant.

\section{Results}

The characteristics of T2D individuals according to CAN status is shown in Table 1. TG concentration and the LAP index presented borderline differences between those with and without definitive CAN (Fig. 1).

Plasma concentrations of TNF, IL10 and LTB4 differed significantly among the groups without CAN, with incipient CAN and with definitive CAN. For TNF and IL10, Dunn's post-test did not show differences between groups while concentration of LTB4 was higher in those presenting incipient CAN $\left(69.7 \pm 16.6 \mathrm{pg} \mathrm{mL}^{-1}\right)$ and definitive CAN $\left(71.5 \pm 15.7 \mathrm{pg} \mathrm{mL}^{-1}\right)$ versus those without CAN $\left(57.0 \pm 13.9 \mathrm{pg} \mathrm{mL}^{-1}\right)$. When the groups with and without definitive CAN were compared, TNF and LTB4 concentrations were significantly higher in the group with definitive CAN while IL10 concentration was significantly lower in this group in comparison to those without definitive CAN (Table 1). After adjustment for confounding variables, only LTB4 concentration 
Table 1 Demographic, clinical and biochemical characteristics of type 2 diabetes individuals sorted according to the status of cardiovascular autonomic neuropathy (CAN)

\begin{tabular}{|c|c|c|c|}
\hline $\begin{array}{l}\text { Demographic. clinical and biochemical } \\
\text { characteristics }\end{array}$ & Without definitive CAN & With definitive CAN & $P$ value \\
\hline$n$ & 85 & 44 & \\
\hline Age (years) & $63(60-67)$ & $62(58-67)$ & 0.43 \\
\hline Sex (\% female) & 60 & 65 & 0.56 \\
\hline Ethnicity (Caucasoid/Negroid/Asiatic) (\%) & $68 / 28 / 4$ & $73 / 27 / 0$ & 0.60 \\
\hline Body mass index $\left(\mathrm{kg} \mathrm{m}^{2}\right)$ & $29.6(26.4-35.7)$ & $28.8(25.9-33.3)$ & 0.35 \\
\hline Waist circumference (cm) & $103(97-115)$ & $102(96-110)$ & 0.91 \\
\hline Arterial hypertension (\%) & 74 & 84 & 0.19 \\
\hline Smoking (\%) & 10.6 & 13.6 & 0.61 \\
\hline Total cholesterol $\left(\mathrm{mg} \mathrm{dL}^{-1}\right)$ & $193(165-234)$ & $203(167-233)$ & 0.60 \\
\hline $\mathrm{HDL}\left(\mathrm{mg} \mathrm{dL}^{-1}\right)$ & $47(38-56)$ & $44(35-52)$ & 0.16 \\
\hline $\mathrm{LDL}\left(\mathrm{mg} \mathrm{dL}^{-1}\right)$ & $118(94-150)$ & $113(89-147)$ & 0.52 \\
\hline Triglycerides $\left(\mathrm{mg} \mathrm{dL}^{-1}\right)$ & $144(111-218)$ & $184(132-212)$ & 0.05 \\
\hline Lipid accumulation product index & $71.1(54.4-110.4)$ & $80.5(60.1-151.4)$ & 0.06 \\
\hline \multicolumn{4}{|l|}{ Diabetes status } \\
\hline Diabetes duration (years) & $8(4-13)$ & $9(4-20)$ & 0.34 \\
\hline $\mathrm{HbA}_{1 \mathrm{C}}(\%)$ & $7.3(6.2-9.2)$ & $7.5(6.4-9.1)$ & 0.94 \\
\hline$\left(\mathrm{mmol} . \mathrm{mol}^{-1}\right)$ & $56(44-77)$ & $58(46-76)$ & \\
\hline eGFR $<60$ mL.min ${ }^{-1} .1 .73 m^{2}(\%)$ & 16 & 11 & 0.57 \\
\hline Distal symmetric polyneuropathy (\%) & 11.7 & 13.6 & 0.75 \\
\hline \multicolumn{4}{|l|}{ Inflammatory mediators } \\
\hline Leukotriene B4 (pg mL ${ }^{-1}$ ) & $63.1 \pm 16.4$ & $71.5 \pm 15.7$ & 0.006 \\
\hline Tumor necrosis factor $\left(\mathrm{pg} \mathrm{mL}^{-1}\right)$ & $1.9 \pm 7.9$ & $7.4 \pm 36.0$ & 0.001 \\
\hline Interleukin 1B (pg mL $\left.{ }^{-1}\right)$ & $23.6 \pm 106.3$ & $9.2 \pm 18.1$ & 0.32 \\
\hline Interleukin $10\left(\mathrm{pg} \mathrm{mL}^{-1}\right)$ & $5.5 \pm 13.5$ & $3.8 \pm 14.2$ & 0.002 \\
\hline
\end{tabular}

Data are expressed as median (interquartile range), except for the inflammatory mediators, which are expressed as mean \pm SD. eGFR: estimated glomerular filtration rate

HDL: High-density lipoprotein; LDL: Low-density lipoprotein. Arterial hypertension defined as systolic/diastolic blood pressure $>140 / 90 \mathrm{mmHg}$ or use of antihypertensive drugs not for renal protection purposes; Hypercholesterolemia defined as an $\mathrm{LDL}>100 \mathrm{mg} \cdot \mathrm{dL}^{-1}$ or use of statin. Differences between groups were assessed by the Wilcoxon and by the Pearson's $x^{2}$ tests. Significantly different variables are shown in italic

remained significantly different between the groups with and without definitive CAN (Table 2).

Plasma concentration of LTB4 did not correlate with the degree of glycemic control as evaluated by $\mathrm{HbA1c}$ $(\rho=-0.015 ; P=0.867)$ or with insulin resistance as evaluated by the LAP index $(\rho=-0.093 ; P=0.2985)$. However, when T2D individuals were sorted by sex, a borderline weak correlation was found between LTB4 concentration and the LAP index in women $(\rho=0.200$; $P=0.082$ ) (Fig. 1).

Table 2 Association between inflammatory mediators and definitive cardiac autonomic neuropathy after adjustment for confounding variables

\begin{tabular}{|c|c|c|c|c|c|}
\hline & & TNF & IL10 & IL1B & LTB4 \\
\hline Model 1 & Unadjusted & $P=0.001$ & $P=0.002$ & $P=0.32$ & $P=0.006$ \\
\hline Model 2 & Adjusted for sex and age & $P=0.18$ & $P=0.47$ & $P=0.51$ & $P=0.006$ \\
\hline Model 3 & Adjusted for sex, age and body mass index (BMI) & $P=0.83$ & $P=0.32$ & $P=0.60$ & $P=0.001$ \\
\hline Model 4 & Adjusted for sex, age, BMI, and waist circumference (WC) & $P=0.17$ & $P=0.54$ & $P=0.93$ & $P=0.016$ \\
\hline Model 5 & $\begin{array}{l}\text { Adjusted for sex, age, BMI, WC, diabetes duration, HbA1c, cholesterol, } \\
\text { triglycerides, arterial hypertension, eGFR, and use of ACEi }\end{array}$ & $P=0.67$ & $P=0.29$ & $P=0.30$ & $P=0.013$ \\
\hline
\end{tabular}

ACEi: Angiotensin-converting enzyme inhibitors; eGFR: estimated glomerular filtration rate; IL: Interleukin, LTB4: Leukotriene B4; TNF: Tumor necrosis factor Significantly different $P$ values are shown in italic 


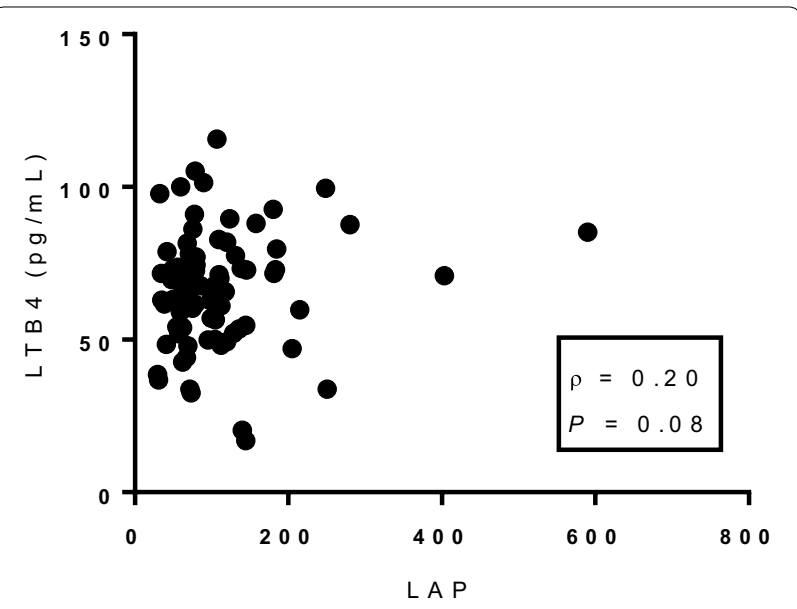

Fig. 1 Correlation between plasma leukotriene B4 (LTB4) concentrations and the Lipid accumulation product (LAP) index in women with type 2 diabetes mellitus

\section{Discussion}

Individuals with $\mathrm{T} 2 \mathrm{D}$ and definitive $\mathrm{CAN}$ presented higher LTB4 plasma concentration than those without this chronic complication. Differences in plasma concentrations of TNF and IL10 between groups with and without CAN lost statistical significance after adjustment for sex and age. On the other hand, LTB4 concentration remained significantly different between the two groups even after adjustment for confounding variables that may interfere with inflammatory markers, such as anthropometric (BMI and WC) and metabolic (glycemic control and dyslipidemia) factors. In the study by Herder et al. for instance, the high concentrations of $\mathrm{C}$-reactive protein and IL6, that were associated with cardiovascular autonomic dysfunction in the unadjusted model, lost statistical significance after adjusting for anthropometric and metabolic variables, showing that the baseline conditions of individuals with T2D by themselves are already associated with subclinical inflammation [10]. In the present study, the increased LTB4 concentration can be attributed to CAN, since adjustment for confounding variables did not alter the association. These findings are in agreement with the ones reported in T1D individuals and corroborate the modulation of the leukotriene pathway by cardiovascular dysautonomia.

Differently from what was observed in T1D individuals, LTB4 plasma concentration did not correlate with glycemic control [4]. A weak borderline correlation was observed between LTB4 concentration and the LAP index in women. Although LTB4 has already been implicated in insulin resistance in rodent models [2, 11, 12], to the best of the authors' knowledge, there are no clinical studies correlating plasma LTB4 concentration with markers of insulin resistance. Thus, studies in larger independent populations are warranted to further investigate the participation of LTB4 in this metabolic derangement, since the present study has a small sample size as its main limitation.

\section{Conclusion}

In the T2D setting, circulating LTB4 concentration seems to be associated with CAN. As already proposed for T1D [4], this inflammatory mediator may exacerbate the cardiovascular burden imposed by CAN, since there is evidence from preclinical studies that LTB4 participates in the development of atherosclerosis [13] by inducing chemoattraction of monocytes and their conversion to foam cells [14] and smooth muscle cells migration and proliferation. The expression of LTB4 receptors in human atherosclerotic lesions [15] and the inhibition of lesions progression by an antagonist of LTB4 receptors in a mouse atherosclerosis model [16] corroborate the proatherogenic effects of this lipid mediator.

\section{Abbreviations \\ ACEi: Angiotensin-converting enzyme inhibitors; BMI: Body mass index; CAN: Cardiovascular autonomic neuropathy; DM: Diabetes mellitus; eGFR: Estimated glomerular filtration rate; EIA: Enzyme immunoassays; ELISA: Enzyme-Linked Immunosorbent Assay; HDL: High-density lipoprotein; HR: Heart rate; IL: Interleukin; LAP: Lipid accumulation product; LDL: Low-density lipoprotein; LTB4: Leukotriene B4; SD: Standard deviation; T1D: Type 1 diabetes mellitus; T2D: Type 2 diabetes mellitus; TG: Triglycerides; TNF: Tumor necrosis fator; WC: Waist circumference.}

\section{Acknowledgements}

Not applicable.

\section{Authors' contributions}

JAJN designed the study and collected clinical data; MRM collected clinical and biochemical data and performed CAN evaluation; TR performed analyses of the inflammatory mediators; DPSB performed statistical analyses; CGDC performed CAN evaluation; RA collected clinical and biochemical data; MSQ participated in the design of the study; SJ participated in the design of the study and obtained funding; and MLC-G designed the study and wrote the paper. All authors read and approved the final manuscript.

\section{Funding}

This work as supported by a grant from Fundacao de Amparo a Pesquisa do Estado de Sao Paulo (FAPESP) to SJ (2013/15719-0). SJ and MLC-G are recipients of Conselho Nacional de Desenvolvimento Científico e Tecnológico (CNPq) fellowships.

\section{Availability of data and materials}

The data used to support the findings of this study are available from the corresponding author upon request.

\section{Ethics approval and consent to participate}

This study was performed in compliance with the Declaration of Helsinki, after approval by the institutional ethics committees (Universidade Nove de Julho, \# 81249417.1.0000.5511; Secretaria Municipal da Saude de São Paulo, \# 81249417.1.3001.0086). All participants signed informed consent.

\section{Consent for publication}

Not applicable. 


\section{Competing interests}

The authors declare that they have no competing interests.

\section{Author details}

${ }^{1}$ Programa de Pos-Graduação Em Medicina, Universidade Nove de Julho (UNINOVE), Rua Vergueiro 235, $2^{\circ}$ subsolo, Pos-graduação, Sao Paulo CEP: 01504-001, Brazil. ${ }^{2}$ Unidade Básica de Saúde Dra. Ilza Weltman Hutzler. Rua Coronel Walfrido de Carvalho, Sao Paulo CEP: 02472-180, Brazil. ${ }^{3}$ Laboratório de Imunofarmacologia, Departamento de Imunologia, Instituto de Ciências Biomédicas, Universidade de São Paulo, Av. Prof. Lineu Prestes, 1730, Sao Paulo CEP: 05508-900, Brazil. ${ }^{4}$ Laboratório de Carboidratos E Radioimunoensaio (LIM-18) Do Hospital das Clínicas HCFMUSP, Faculdade de Medicina, Universidade de São Paulo, Avenida Dr. Arnaldo, 455, Sala 3321, Sao Paulo CEP: 01246-903, Brazil.

Received: 25 July 2020 Accepted: 2 November 2020

Published online: 12 November 2020

\section{References}

1. Yu L, Li Y, Du C, Zhao W, Zhang H, Yang Y, et al. Pattern recognition receptor-mediated chronic inflammation in the development and progression of obesity-related metabolic diseases. Mediators Inflamm. 2019;2019:5271295.

2. Li P, Oh DY, Bandyopadhyay G, Lagakos WS, Talukdar S, Osborn O, et al. LTB4 promotes insulin resistance in obese mice by acting on macrophages, hepatocytes and myocytes. Nat Med. 2015;21(3):239-47.

3. Domingueti CP, Dusse LM, Carvalho M, de Sousa LP, Gomes KB, Fernandes AP. Diabetes mellitus: The linkage between oxidative stress, inflammation, hypercoagulability and vascular complications. J Diabetes Complicat. 2016;30(4):738-45.

4. Santos-Bezerra DP, Filqueiras LR, Monteiro MB, Admoni SN, Perez RV Cavaleiro AM, et al. Leukotrienepathway activation associates with poor glycemic control and with cardiovascular autonomic neuropathy in type 1 diabetes. Mediators Inflamm. 2020;23(2020):5704713.

5. Pavlov VA, Tracey KJ. The vagus nerve and the inflammatory reflex-linking immunity and metabolism. Nat Rev Endocrinol. 2012;8(12):743-54.

6. Reis de Matos M, Santos-Bezerra DP, das Graças Dias Cavalcante C, de Xavier Carvalho J, Leite J, Neves JAJ, et al. Distal symmetric and cardiovascular autonomic neuropathies in Brazilian individuals with type 2 diabetes followed in a primary health care unit. Int J Environ Res Pub Health. 2020;17(9):3232.

7. Vinik Al, Ziegler D. Diabetic cardiovascular autonomic neuropathy. Circulation. 2007;115(3):387-97.

8. Kahn HS. The "lipid accumulation product" performs better than the body mass index for recognizing cardiovascular risk: a population-based comparison. BMC Cardiovasc Disord. 2005;5:26.

9. Fiorentino TV, Marini MA, Succurro E, Andreozzi F, Sesti G. Relationships of surrogate indexes of insulin resistance with insulin sensitivity assessed by euglycemic hyperinsulinemic clamp and subclinical vascular damage. BMJ Open Diabetes Res Care. 2019;7(1):e000911.

10. Herder C, Schamarek I, Nowotny B, Carstensen-Kirberg M, Straßburger

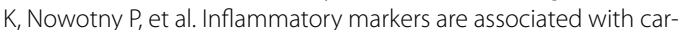
diac autonomic dysfunction in recent-onset type 2 diabetes. Heart. 2017;103(1):63-70

11. Spite M, Hellmann J, Tang Y, Mathis SP, Kosuri M, Bhatnagar A, et al. Deficiency of the leukotriene B4 receptor, BLT-1, protects against systemic insulin resistance in diet-induced obesity. J Immunol. 2011;187(4):1942-9.

12. Mothe-Satney I, Filloux C, Amghar H, Pons C, Bourlier V, Galitzky J, et al. Adipocytes secrete leukotrienes: contribution to obesity-associated inflammation and insulin resistance in mice. Diabetes. 2012;61(9):2311-9.

13. Peters-Golden M, Henderson WR. Leukotrienes. N Engl J Med. 2007;357(18):1841-54.

14. Subbarao K, Jala VR, Mathis S, Suttles J, Zacharias W, Ahamed J, Ali H, et al. Role of leukotriene B4 receptors in the development of atherosclerosis: potential mechanisms. Arterioscler Thromb Vasc Biol. 2004:24(2):369-75.

15. Bäck M, Bu D-x, Bränström R, Sheikine Y, Yan Z, Hansson GK. Leukotriene B4 signaling through NF-kappaB-dependent BLT1 receptors on vascular smooth muscle cells in atherosclerosis and intimal hyperplasia. Proc Natl Acad Sci USA. 2005:102(48):17501-6.

16. Ketelhuth DFJ, Hermansson A, Hlawaty H, Letourneur D, Yan Z-Q, Bäck M. The leukotriene B4 receptor (BLT) antagonist BIIL284 decreases atherosclerosis in ApoE-/- mice. Prostaglandins Other Lipid Mediat. 2015;121(Pt A):105-9.

\section{Publisher's Note}

Springer Nature remains neutral with regard to jurisdictional claims in published maps and institutional affiliations.
Ready to submit your research? Choose BMC and benefit from:

- fast, convenient online submission

- thorough peer review by experienced researchers in your field

- rapid publication on acceptance

- support for research data, including large and complex data types

- gold Open Access which fosters wider collaboration and increased citations

- maximum visibility for your research: over $100 \mathrm{M}$ website views per year

At $\mathrm{BMC}$, research is always in progress.

Learn more biomedcentral.com/submissions 